\title{
TECHNOLOGY OF PREPARATION OF BARIUM AND MAGNESIUM HYDROXIDE NANODISPERSION AND POSSIBILITIES OF THEIR USE IN MONUMENT CARE
}

\author{
Klára Kroftová $^{a, *}$, David ŠKoda ${ }^{b}$, Ivo KuŘitka $^{b}$, Jan KubÁt $^{c}$ \\ ${ }^{a}$ Czech Technical University in Prague, Faculty of Civil Engineering, Dept. of Architecture, Thákurova 7, 16629 \\ Prague 6, Czech Republic \\ ${ }^{b}$ Centre of Polymer Systems, Tomas Bata University in Zlin, Tř. Tomáše Bati 5678, 76001 Zlín, Czech Republic \\ ${ }^{c}$ Czech Technical University in Prague, Faculty of Civil Engineering, Dept. of Building Structures, Thákurova 7, \\ 16629 Prahue 6, Czech Republic \\ * corresponding author: Klara.Kroftova@fsv.cvut.cz
}

\begin{abstract}
An application of hydroxide nanoparticles in preservation of cultural heritage attracted great interest. The nanodispersions of calcium, magnesium or barium hydroxides exhibit high performance in consolidation abilities. In this work we focused on preparation of magnesium and barium hydroxide nanoparticles. For the synthetic procedure we used acetate precursors and sodium hydroxide. Obtained particles were dispersed in 2-propanol. Hydroxide nanoparticles were characterized by powder $\mathrm{X}$-Ray diffraction, infrared spectroscopy and scanning electron microscopy. It was observed that smaller particles were achieved in case of magnesium hydroxide. Presented work demonstrates that this reaction procedure can be applied for preparation of materials used in cultural heritage preservation.
\end{abstract}

KEYwords: Magnesium, barium, hydroxide, nanodispersion, cultural heritage, preservation, consolidation.

\section{INTRODUCTION}

Present cultural heritage preservation is based on the requirements of reversible and noninvasive interventions in historical structures and buildings in general, so as not to disturb the intact parts of the structure and to lose historical values. For these reasons, at the present time, the reconstruction of protected monuments places high demands on the preservation of historical matter itself and the preservation of the authentic expression of the object as a representative of the value of old age. Within the "minimal invasion" perspective, new, virtually invisible methods are highly desirable that can not only stop but also "reverse" the degradation processes of artworks, can restore the original appearance of artifacts. In recent decades, the meaning of nanotechnology has raised in the area of cultural heritage protection, which brings new ways of protecting building structures by using specific, functionalized properties of materials due to increasing the surface area ratio of particle surface to particle volume of nanomaterials. Compared with macro-materials, nanomaterials represent extremely high "performance" in contrast to very low material consumption. Nanomaterials can, for example, due to a great penetration into the pore system and yet preservation of the original material, facilitate the cleaning of varnished surfaces (graffiti), provide temporary stiffening of the plastered surface, enhance UV protection, provide self-cleaning technology, and more. It can be reasonably assumed that the use of nanotechnologies could provide new protection options, espe- cially the surfaces of building materials, which aim at speeding up, facilitating or slowing chemical reactions and providing various protective functions of surface treatments etc. [1], 2], 3], 4], [5. Practical examples include the consolidation and consolidation of plaster surfaces and natural stone porous elements using nanomaterials based on calcium or barium hydroxide, in some cases sulphates [6, [7]. The most common nanomaterials used in restoration are water-soluble inorganic nanomaterials, especially calcium hydroxide and magnesium hydroxide [8, 9. Calcium hydroxide nanoparticles can be used to deacidify, consolidate and solidify the material on the basis of "remineralization". Combined with the barium hydroxide solution, it also serves to remove sulphates and the so-called Ferroni-Dini method to in situ revitalize the original binder in paintings [10]. Magnesium hydroxide can be successfully applied when restoring and preserving wood and artifacts from paper. Just like $\mathrm{Ca}(\mathrm{OH})_{2}$ and $\mathrm{Mg}(\mathrm{OH})_{2}$, carbonates react with airborne $\mathrm{CO}_{2}$ to strengthen and fill the damaged parts of the restored monuments. In addition, $\mathrm{Mg}(\mathrm{OH})_{2}$, for example, slows the cellulose photodegradation [11. Herein we present a synthesis of barium and magnesium hydroxides from barium and magnesium acetate precursors, respectively. These materials were prepared by precipitation technique with sodium hydroxide in 2-propanol. Obtained materials were dispersed in 2-propanol to form suspensions. 


\section{MATERIALS AND METHODS}

The NAKI DG16P02M055 research project "Development and Research of Materials, Methods and Technologies for the Restoration, Preservation and Strengthening of Historic Masonry Constructions and Surfaces and Systems of Preventive Conservation of Cultural Heritage Buildings Threatened by Anthropogenic and Natural Hazards (2016 - 2022, MK0/DG)" addresses the issues of strengthening historic surface plaster layers with lime nanosuspensions. The institutions currently participating in the research project are the Centre of Polymeric Materials, TBU in Zlín and the Faculty of Civil Engineering, CTU in Prague.

\subsection{ChemicAls}

Barium acetate $\left(\mathrm{Ba}\left(\mathrm{CH}_{3} \mathrm{COO}\right)_{2}, M_{w}: 255.42 \mathrm{~g} / \mathrm{mol}\right.$, $99 \%$, Sigma Aldrich), Magnesium acetate tetrahydrate $\left(\mathrm{Mg}\left(\mathrm{CH}_{3} \mathrm{COO}\right)_{2} \cdot{ }_{4} \mathrm{H}_{2} \mathrm{O}, M_{w}: 214.45 \mathrm{~g} / \mathrm{mol}\right.$, Sigma Aldrich), Sodium hydroxide (p.a., Sigma Aldrich) and 2-propanol (p.a. VWR).

\subsection{SYNTHESES}

Typical synthesis of $\mathrm{Mg}(\mathrm{OH})_{2}$ was performed as follows: Magnesium acetate tetrahydrate (2.00 g) was added into $200 \mathrm{ml}$ of 2-propanol under vigorous stirring. Afterwards, $50 \mathrm{ml}$ of aqueous sodium hydroxide $(1.16 \mathrm{~g})$ solution was dropwise added into stirred magnesium acetate suspension. After addition of sodium hydroxide, the reaction mixture was stirred at room temperature for 24 hours and white cloudy suspension was observed. Solid product was separated by centrifugation, dried at $90{ }^{\circ} \mathrm{C}$ and characterized by powder X-Ray diffraction, scanning electron microscopy and FTIR spectroscopy. Typical synthesis of $\mathrm{Ba}(\mathrm{OH})_{2}$ was performed by the same manner as in the case of previous magnesium hydroxide. Barium acetate $(3,00$ g) was added into $200 \mathrm{ml}$ of 2-propanol under vigorous stirring. Afterwards, $50 \mathrm{ml}$ of aqueous sodium hydroxide $(0.94 \mathrm{~g})$ solution was dropwise added into stirred barium acetate suspension. After addition of sodium hydroxide, the reaction mixture was stirred at room temperature for 24 hours and white precipitate was observed. Solid product was separated by centrifugation, dried at $90^{\circ} \mathrm{C}$ and characterized by powder $\mathrm{X}$-Ray diffraction, scanning electron microscopy and FTIR spectroscopy.

\subsection{Characterization techniques}

The powder XRD patterns were recorded on a Rigaku MiniFlex 600 equipped with a $\operatorname{CoK} \alpha(\lambda=1.7903 \AA) \mathrm{X}$ ray tube $(40 \mathrm{kV}, 15 \mathrm{~mA})$. The IR spectra were recorded on a Thermo Scientific Nicolet 6700 spectrometer using an ATR technique with the diamond crystal (4000-400 cm-1, resolution $2 \mathrm{~cm}-1,64$ scans). The SEM images and EDX analysis were recorded on a Nova NanoSEM (FEI) with Schotky field emission electron source $(0.02-30 \mathrm{keV})$ and TLD detector at $5 \mathrm{kV}$.

\subsection{Results AND DISCUSSION}

Barium hydroxide and Magnesium hydroxide were prepared by precipitation reaction of acetate precursors and sodium hydroxide aqueous solution in 2-propanol. Crystalline phases of obtained products were determined by powder X-Ray diffraction. As illustrated in Fig. 1a), diffractions of prepared $\mathrm{Mg}(\mathrm{OH})_{2}$ match with reference diffractogram of brucite (JCPDS card 01-0715972 ) and thus successful formation of $\mathrm{Mg}(\mathrm{OH})_{2}$ crystalline phase is confirmed. Since the observed diffractions are broad, nanostructured character of this sample can be expected. In the case of prepared $\mathrm{Ba}(\mathrm{OH})_{2}$ sample (Fig. 1b)), diffractions of $\mathrm{Ba}(\mathrm{OH})_{2} \cdot \mathrm{H}_{2} \mathrm{O}$ (JCPDS 00-26-0154) and $\mathrm{Ba}(\mathrm{OH})_{2} \cdot{ }_{3} \mathrm{H}_{2} \mathrm{O}$ (JCPDS 01-077-2333) were assigned. This observation corresponds with reported data of barium hydroxide chemistry with the hydrate structure $\mathrm{Ba}(\mathrm{OH})_{2} \cdot\left(\mathrm{H}_{2} \mathrm{O}\right) \mathrm{x}$. [12].
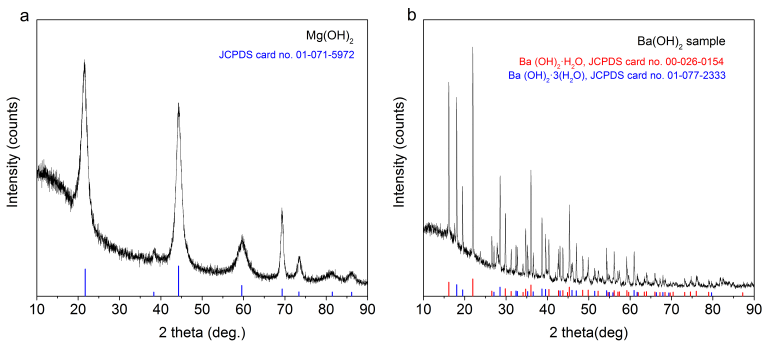

Figure 1. a) Powder XRD diffractogram of prepared $\mathrm{Mg}(\mathrm{OH})_{2}$ sample; b) Powder XRD diffractogram of prepared $\mathrm{Ba}(\mathrm{OH})_{2}$ sample.

FTIR spectroscopy was used for characterization of functional groups and chemical bonds in prepared samples. Fig. 2 displays the FTIR spectrum of $\mathrm{Mg}(\mathrm{OH})_{2}$ sample. Sharp vibrational band at $3696 \mathrm{~cm}-$ 1 corresponds to stretching modes of $-\mathrm{OH}$ groups in $\mathrm{Mg}(\mathrm{OH})_{2}$. The $\mathrm{Mg}-\mathrm{O}$ bonds are represented with the vibrational band below $500 \mathrm{~cm}-1$. Broad band at 3350 cm-1 is assigned to $-\mathrm{OH}$ groups of adsorbed water or 2-propanol. Vibrational bands between 1700 and $1250 \mathrm{~cm}-1$ are attributed to residual acetoxy groups and groups of 2-propanol solvent. In the case of barium hydroxide sample, FTIR spectrum is little bit complicated in compared to magnesium hydroxide. Sharp vibrational band of $-\mathrm{OH}$ stretching modes in $\mathrm{Ba}(\mathrm{OH})_{2}$ is located at $3574 \mathrm{~cm}-1$ (Fig. 2). This observation confirms the presence of $\mathrm{Ba}(\mathrm{OH})_{2}$. Other vibrational bands recorded in FTIR spectrum can be assigned to 2-propanol, residual acetoxy species and undefined reaction byproducts.

Scanning electron microscopy was employed in order to investigate a morphology of prepared samples. As depicted in Fig. $3 . \mathrm{Mg}(\mathrm{OH})_{2}$ formed needle shape nanoparticles with the lengths about $100 \mathrm{~nm}$. In case of $\mathrm{Ba}(\mathrm{OH})_{2}$ sample the size of particles is significantly higher (about $500 \mathrm{~nm}$ ). This behavior is caused mostly by a different chemistry between magnesium and barium. For example, barium hydroxide is stronger base 

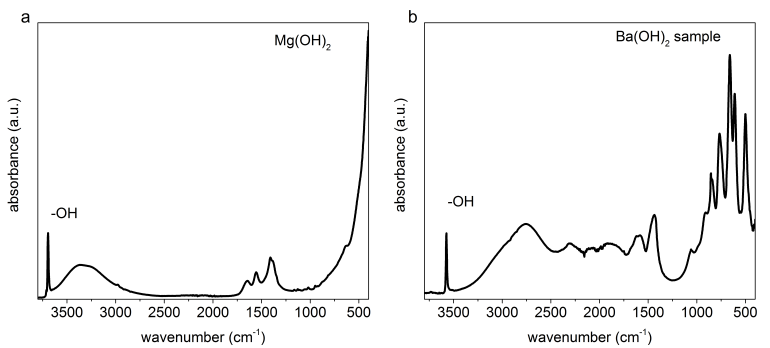

Figure 2. a) FTIR spectrum of $\mathrm{Mg}(\mathrm{OH})_{2}$ sample; b) FTIR spectrum of $\mathrm{Ba}(\mathrm{OH})_{2}$ sample.

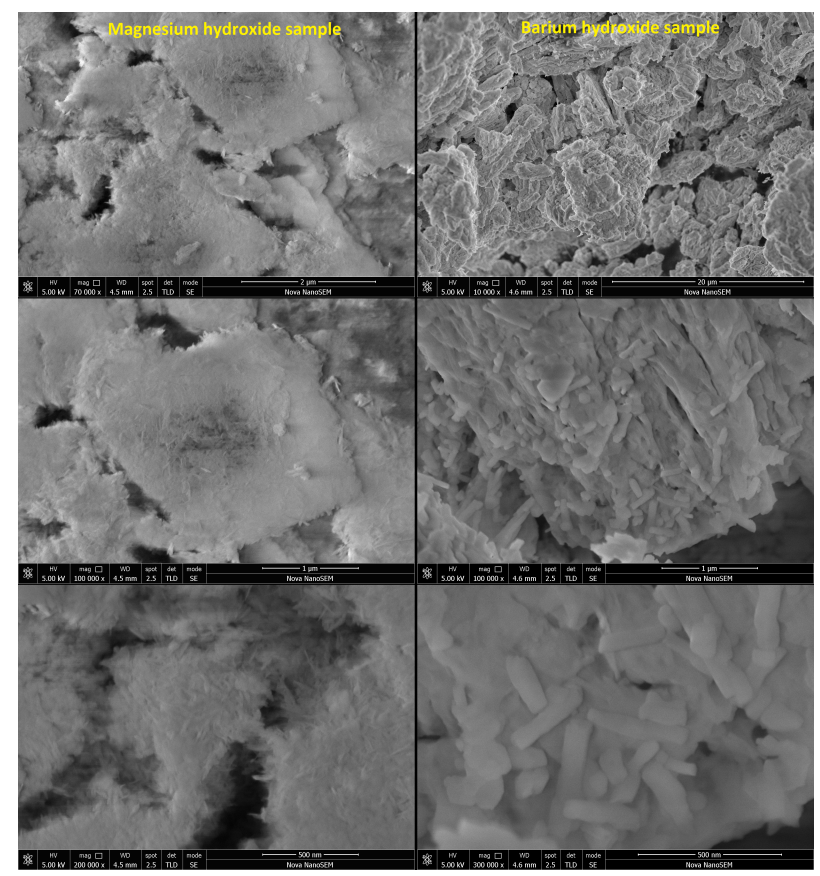

Figure 3. SEM images of product powders. Left column: $\mathrm{Mg}(\mathrm{OH})_{2}$ sample, right column $\mathrm{Ba}(\mathrm{OH})_{2}$ sample.

than magnesium hydroxide and this can affect the final form of prepared sample. Both samples exhibit the character of aggregated particles. These aggregates can be for example separated in ultrasonic bath.

\section{Conclusions}

his work reports the preparation of magnesium hydroxide and barium hydroxide nanoparticles via precipitation reaction of acetate precursors with sodium hydroxide. Analyses of both products confirmed the formation magnesium hydroxide and barium hydroxide crystalline phases and thus the use of acetate precursors in these reactions is suitable. In the case of magnesium hydroxide sample small needle-like crystals with the length about $100 \mathrm{~nm}$ were observed. Barium hydroxide sample revealed bigger particles. From this point of view we can conclude that presented synthesis is more suitable for preparation of magnesium hydroxide nanoparticles. Obtained nanoparticles can be dispersed in 2-propanol and this dispersion can be supported by use of ultrasonic bath. Anyway, both products dispersed in 2-propanol have the potential to be used in cultural heritage restoration.

\section{ACKNOWLEDGEMENTS}

This article was written as part of the NAKI DG16P02M055 research project "Development and Research of Materials, Methods and Technologies for the Restoration, Preservation and Strengthening of Historic Masonry Constructions and Surfaces and Systems of Preventive Conservation of Cultural Heritage Buildings Threatened by Anthropogenic and Natural Hazard (2016 2022, MK0/DG)".

\section{REFERENCES}

[1] J. Rathouský. Micellar solutions and microemulsions for the cleaning of historical materials. nanomaterials in heritage conservation.

[2] L. Machačko, et al. Konsolidace historických omítkových vrstev v druhém NP ambitu bývalého kláštera Rosa Coeli v Dolních Kounicích pomocí vápenné nanosuspenze Calosil, 2012.

[3] V. Daniele, et al. The nanolimes in cultural heritage conservation: Characterisation and analysis of the carbonatation process, journal of cultural heritage, 2008.

[4] D. Chelazzi, et al. Hydroxide nanoparticles for cultural heritage: Consolidation and protection of wall paintings and carbonate materials. Journal of Colloid Interface Science 2016.

[5] L. Ventola, et al. Traditional organic additives improve lime mortars: New old materials for restoration and building natural stone fabrics, construction and building materials, 2011.

[6] M. Drdácky, Z. Slízkova. Nanomateriály v péči o památky. Akamedický bulletin (10):10-11, 2012.

[7] R. Giorgi, et al. Nanoparticles for cultural heritage conservation: Kalcium and barium hydroxide nanoparticles for wall painting consolidation. Chemistry a European Journal 16:9374-9382, 2010.

[8] P. Baglioni, R. Giorgi. Soft and hard nanomaterials for restoration and conservation of cultural heritage. Soft Matter 2:293-303, 2006.

[9] A. Blee, J. Matisons. Nanoparticles and the conservation of cultural heritage. Materials Forum 32:121-128, 2007.

[10] P. Baglioni, et al. Nanotechnology in wall painting conservation conference: Meeting on self-assembly - the future pp. 32-41, 2003.

[11] R. Giorgi, et al. Nanoparticles of $\mathrm{Mg}(\mathrm{OH})_{2}$ : Synthesis and Application to Paper Conservation, Langmuir, 2005.

[12] R. Kresse, U. Baudis, P. Jäger, et al. Barium and barium compounds. In Ullmann's Encyclopedia of Industrial Chemistry 2007. 